\title{
Wetting Properties of Polyetheretherketone Plasma Activated and Biocoated Surfaces
}

\author{
Kacper Przykaza *D, Klaudia Woźniak, Małgorzata Jurak and Agnieszka Ewa Wiącek \\ Department of Physical Chemistry-Interfacial Phenomena, Faculty of Chemistry, University of Maria \\ Curie-Skłodowska, Maria Curie-Skłodowska Sq. 3, 20-031 Lublin, Poland; \\ klaudia.wozniak@poczta.umcs.lublin.pl (K.W.); malgorzata.jurak@poczta.umcs.lublin.pl (M.J.); \\ a.wiacek@poczta.umcs.lublin.pl (A.E.W.) \\ * Correspondence: przykaza.kacper@poczta.umcs.lublin.pl
}

Received: 29 December 2018; Accepted: 12 March 2019; Published: 16 March 2019

\begin{abstract}
Polyetheretherketone (PEEK) biomaterial is a polymer which has been widely used since the early 90s as a material for human bone implant preparations. Nowadays it is increasingly used due to its high biocompatibility and easily modeling, as well as better mechanical properties and price compared to counterparts made of titanium or platinum alloys. In this paper, air low-temperature and pressure plasma was used to enhance PEEK adhesive properties as well as surface sterilization. On the activated polymeric carrier, biologically-active substances have been deposited with the Langmuir-Blodgett technique. Thereafter, the surface was characterized using optical profilometry, and wettability was examined by contact angle measuring. Next, the contact angle hysteresis (CAH) model was used to calculate the surface free energy of the modified surface of PEEK. The variations of wettability and surface free energy were observed depending on the deposited monolayer type and its components.
\end{abstract}

Keywords: PEEK polymer; plasma activation; Langmuir-Blodgett coatings; wettability; surface free energy

\section{Introduction}

Polyaryletherketones (PAEK) are high-performance thermoplastic polymers with great mechanical and dielectric properties such as electrical resistivity, compressive strength, and elastic and Young modules. One of them is polyetheretherketone (PEEK), semicrystalline linear polymer, whose degree of crystallinity is between 30 and 35 percent. In its structure, there are aromatic rings combined by oxygen bridges and esters functional groups (Figure 1) [1-5]. Owing to all of the previously mentioned properties, PEEK is used for parts of machines which work in hard conditions and also is used to prepare prostheses and implants of back, skull, facial, and spine bones [1,5-8].

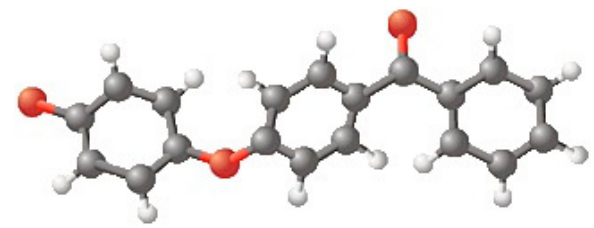

Figure 1. The polyetheretherketone (PEEK) structure.

Polymers used in medicine should be biocompatible and non-toxic. However, the low surface energy of PEEK causes huge problems with integration between implant or prosthesis and the surrounding tissues. Thus, the strength of the adhesion determines the biocompatibility of polymer 
with a positive response of the human body and avoidance of undesirable effects such as infections, allergies, or implant rejection [6,7]. That is why the PEEK surface needs to be modified. One of the physical methods for modification is plasma treatment. As a result, the new groups are created on the surface, and then its character is changed. Therefore, it is possible to form physisorbed or chemisorbed monolayers on activated polymer support. Beyond polymers, the standard materials for many implants designed are titanium, bioactive glass, diamond-like carbon, or ceramics $[2,9,10]$. The commonly used and well-accepted materials for the film formation on implant surfaces are lipids/phospholipids or their polymeric derivatives [11,12] that mimic natural cell membranes [10]. They are applied for the preparation of the implant coatings by means of numerous techniques, such as Langmuir-Blodgett/Schaefer, solution spreading, self-assembly, and liposome adhesion techniques [13-16]. The obtained films with lipids should strengthen the intimate interface between the cells and the artificial material [17]. As a consequence of that, the platelets adhesion, blood clot formation, and the amount of adhering bacteria can be limited. This facilitates the combating or eradication of side effects (e.g., infections) on these surfaces [15]. Therefore, in the development of medical devices, the modifications, including plasma treatment and lipid coatings, are conducted simultaneously with the investigations of bacterial biofilm formation on the implants $[9,18]$.

In this paper, the low-temperature air plasma was used to activate the PEEK surface for removal of any pollutions $[8,19]$ and as the pre-deposition process followed by immobilization of biologically active substances, i.e., 1,2-dipalmitoyl-sn-glycero-3-phosphocholine (DPPC), cholesterol (Chol) and cyclosporine A (CsA) (Figure 2), by means of the Langmuir-Blodgett technique. DPPC and Chol were chosen because they are the main components of human cell membranes, thus mimicking their structure and behavior. CsA is a cyclic polypeptide used as an immunosuppressant to prevent implant rejection. Simultaneous use of CsA with DPPC or Chol allows for the binding of both compounds as the mixed film to the polymer surface. This can strengthen their effect on organisms which leads to the increased biocompatibility, and finally, the positive response of tissues to the implanted biomaterial.
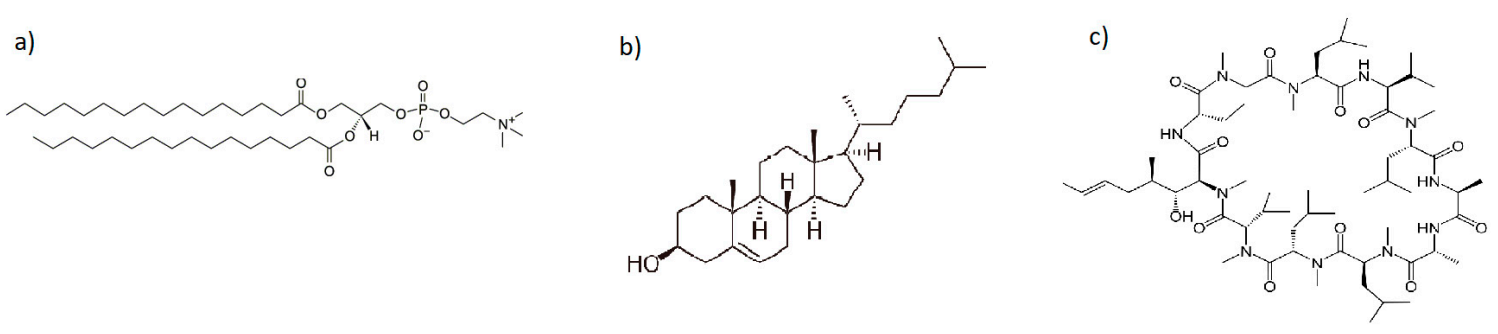

Figure 2. The structure of (a) DPPC,(b) Chol,(c) CsA.

Investigations of surface roughness and the wettability of potential implants are very important due to the different polarities of the tissues contacted with the polymer material. Therefore, it is necessary to select the appropriate type of modification to obtain a polymer surface with the desired surface properties. One of the thermodynamic functions which characterize interactions at the interface quantitatively is the surface free energy. Due to the lack of direct methods for its determination in the literature, there are many theoretical models to evaluate it [20]. In this paper, the model proposed by Chibowski was applied [20,21]. This approach is based on the Young equation and assumes that when an advancing contact angle is measured there is no film behind the liquid's drop. However, during receding contact angle measurements on the three-phase contact line, the liquid film is present behind the drop [20-22]. Taking the above into account, one can derive Equation (1) to calculate the total surface free energy of solid $\gamma_{s}$.

$$
\gamma_{s}=\frac{\gamma_{L}\left(1+\cos \theta_{a}\right)^{2}}{2+\cos \theta_{r}+\cos \theta_{a}}
$$


Equation (1) includes the advancing $\left(\theta_{a}\right)$ and receding $\left(\theta_{r}\right)$ contact angles for one liquid with a well-known surface tension $\left(\gamma_{L}\right)$. In literature, the difference between $\theta_{a}$ and $\theta_{r}$ is called the contact angle hysteresis (CAH) [20]. This phenomenon for thin films is caused by many factors resulting from the nature of molecules and the interactions between them. In addition to the most obvious ones, i.e., the surface roughness and its heterogeneity, the contact angle hysteresis also depends on the surface topography and rigidity of molecules, as well as on the molecular organization on the solid surface $[23,24]$. Moreover, different hysteresis values are determined by the type of measuring liquid used, liquid sorption and/or liquid retention, size, and shape of liquid molecules, and most importantly, interactions at the solid/liquid interface. Therefore, CAH provides additional information about the mechanism of liquid behavior in contact with the solid surface. The advantage of this approach is the possibility to evaluate the total surface free energy from the CAH of one liquid [20-22]. Use of three different liquids gives three different values of energy, which indicates the apparent character of the determined $\gamma_{s}$. However, in most cases, the arithmetic mean is similar to the total surface free energy calculated from other approaches which consider the division of energy into the components (polar and apolar) [20,21]. Additionally, the Chibowski equation works even when the contact angle is equal to zero (total spreading). On the other hand, when the hysteresis is zero, and inserting $\theta_{a}=\theta_{r}=\theta$ to the Equation (1), one can obtain the surface free energy equal to half of the work of adhesion $\left(\frac{1}{2} W_{A}\right)$ [20]. However, even on perfectly-prepared monolayers or mica surface with Angstrom scale roughness, the hysteresis is observed and the CAH model works properly. Therefore, it was used for the determination of the presented below wettability of the thin layers on the polymer support.

\section{Materials and Methods}

The PEEK tiles with dimensions of $20 \times 30 \times 5 \mathrm{~mm}^{3}$ were cut from commercially available TECAPEEK natural (size $1000 \times 500 \times 5 \mathrm{~mm}^{3}$, PROFILEX, Orchów, Poland) and prepared for the modifications according to a defined procedure, which included rinsing with water from the MilliQ system (conductivity of $18.2 \mathrm{M} \Omega \mathrm{cm}$ at $25^{\circ} \mathrm{C}$ ) with the addition of neutral extrane $(1 \mathrm{~mL} / 100 \mathrm{~mL}$ ), rinsing with methanol, and three times with water. During each stage of rinsing, the polymer tiles immersed in washing liquid were exposed to ultrasounds for $15 \mathrm{~min}$. The plates were then dried in a vacuum oven for $24 \mathrm{~h}$ at room temperature and subsequently transferred to a desiccator.

Cleaned polymeric matrices have been subjected to a low-temperature $\left(20^{\circ} \mathrm{C}\right)$ and low-pressure $(0.2 \mathrm{mbar})$ air plasma $(460 \mathrm{~W})$ activation process using Diener Electronic (Germany). In each case, the activation time was $60 \mathrm{~s}$, with a continuous air flow of $22 \mathrm{sccm}$ (standard cubic centimeters per minute). Immediately after the activation process, the monolayers of bioactive substances were transferred with the Langmuir-Blodgett (LB) technique to the polymer surfaces.

Firstly, the activated PEEK plate was attached to the dip-coater arm coupled with the Langmuir-Blodgett trough (LB 2000, KSV, Helsinki, Finland), dipped under the water subphase to carry out coating by pulling out using the LB technique. The scheme of the process is presented in Figure 3.

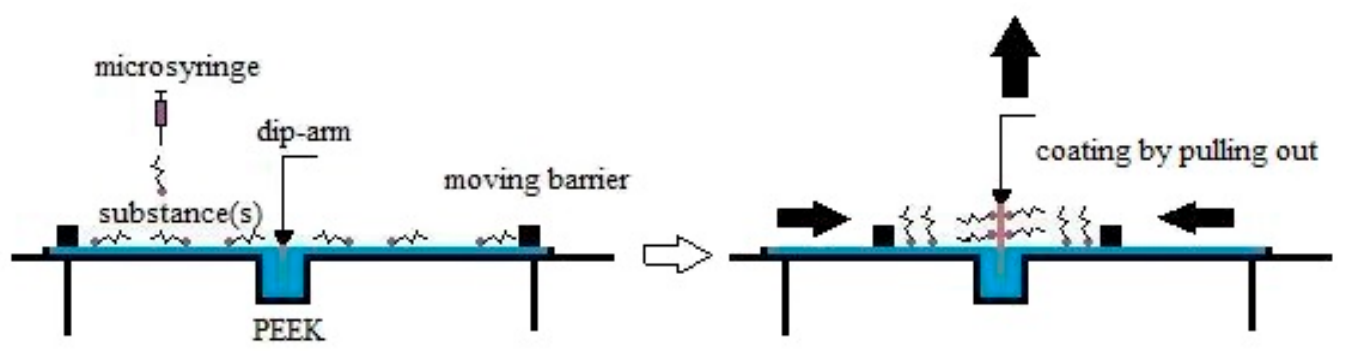

Figure 3. The scheme of coating solid supports using the Langmuir-Blodgett technique by pulling out. 
In order to obtain the self-assembled monolayers, solutions of DPPC, Chol, and CsA (DPPC and Chol were purchased from Sigma-Aldrich, Sain Luis, MS, USA, CsA from Alfa Aesar, Haverhill, MA, USA, with purity above $99 \%$ ) at a concentration of $1 \mathrm{mg} / \mathrm{mL}$ in chloroform: methanol (from Avantor Performance Materials Poland S.A, Gliwice, Poland) in a 4:1 ratio $(v / v)$ were prepared. Mixtures of CsA-DPPC and CsA-Chol were prepared by mixing appropriate volumes of one-component solutions. All systems were used just after preparation and accurate solution volumes were spread using a microsyringe onto the water subphase filling the clean Langmuir trough. After $10 \mathrm{~min}$ of solvent evaporation, the following procedure was done with the LB technique. Moving barriers compressed substances spread onto the air/water interface to obtain the given value of surface pressure, high enough to coat the solid support with the packed monolayer. The surface pressure of the transfer has been chosen based on the $\pi$-A isotherm curves (surface pressure versus area per molecule) as well as reference to the other authors [25]. Values of the transfer parameters are presented in Table 1.

Table 1. Experimental transferring parameters.

\begin{tabular}{cccc}
\hline Substance(s) & $\begin{array}{c}\text { Compression Speed } \\
{[\mathbf{m m} / \mathbf{m i n}]}\end{array}$ & $\begin{array}{c}\text { Surface Pressure during } \\
\text { Transfer }[\mathbf{m N} / \mathbf{m}]\end{array}$ & $\begin{array}{c}\text { Transfer Speed } \\
{[\mathbf{m m} / \mathbf{m i n}]}\end{array}$ \\
\hline DPPC & 20 & 30 & 5 \\
Cholesterol & 20 & 30 & 5 \\
CsA & 20 & 15 & 5 \\
DPPC-CsA & 20 & 15 & 5 \\
Cholesterol-CsA & 20 & 15 & 5 \\
\hline
\end{tabular}

After the transfer process, the samples were dried in vacuum oven for $24 \mathrm{~h}$ at room temperature. Analysis of the obtained surfaces was made on the basis of measurements of the contact angles of three probe liquids with well-defined values of their surface tensions: Water from the MilliQ system, formamide (Acrōs Organics, Geel, Belgium, 99.5\%) and diiodomethane (Sigma-Aldrich, Saint Luis, MS, USA, 99\%). For this purpose, a contact angle measuring kit (DGD ADR model with GBX S.A.R.L) has been used. During the procedure, the temperature, humidity, and inclination of the measuring chamber were kept constant. Moreover, to reduce the influence of moisture from the air, an inert gas, nitrogen, was additionally pumped to the chamber interior. On the modified PEEK surfaces, $6 \mu \mathrm{L}$ drops of the test liquids were deposited with a microsyringe and the advancing contact angles were determined using WinDrop++ software. Next, $2 \mu \mathrm{L}$ of the liquid was sucked back and the receding contact angle of the drop was measured by the same formula [13].

To characterize the changes in the surface topography the optical profilometry was applied. Also, in order to have better insight into polarity changes, the thermodynamic function-total surface free energy (SFE) - has been evaluated based on the contact angle hysteresis (CAH) approach.

\subsection{Surface Roughness Characterization}

Using optical profilometer Bruker Contour GT-K1 (Germany), the surface characterization has been conducted based on the topography of 10 different places on each sample surface $\left(62 \times 47 \mu \mathrm{m}^{2}\right)$. The statistics of $R_{a}$ (average roughness), $R_{q}$ (root-mean square) and $R_{t}$ (peak-to-valley difference) were calculated with the exploit of Vision 4.20 software (Veeco).

Average roughness $\left(R_{a}\right)$ is the mean of the difference, in absolute value, between the average height and that of each single point of the sample:

$$
R_{a}=\frac{1}{n} \sum_{i=1}^{n}\left|Z_{i}-\bar{Z}\right|
$$

where $Z_{i}$ is the observed height at a certain point $i, \bar{Z}$ is the average of the $Z$ values within the given area, and $n$ is the total number of data points within the given area in one image. 


$$
R_{q}=\sqrt{\frac{1}{n} \sum_{i=1}^{n}\left(Z_{i}-\bar{Z}\right)^{2}}
$$

Root-mean-square $\left(R_{q}\right)$ average roughness of the surface, defined as the standard deviation of the elevation - within the given area, was calculated from $R_{a}$ by taking the same measurements, squaring them, dividing the total by the number of measurements, and taking the square root of the result. $R_{q}$ is more sensitive to occasional highs and lows, in comparison $R_{a}$. Peak-to-valley difference $\left(R_{t}\right)$ is the maximum height of the profile:

$$
R_{t}=R_{p}+R_{v}
$$

where $R_{p} / R_{v}$ is the distance between the maximal/minimal point on the surface, respectively, and the mean height of the surface.

The statistics of $R_{a}, R_{q}$ and $R_{t}$ parameters were presented in the next part of manuscript. The obtained standard deviations of the calculated parameters are as follows: $R_{a}(0.10-0.27 \mu \mathrm{m}) ; R_{q}$ $(0.12-0.28 \mu \mathrm{m}) ; R_{t}(0.72-2.82 \mu \mathrm{m})$.

\subsection{Surface Free Energy (SFE) Determination}

Chibowski proposed SFE $\left(\gamma_{s}\right)$ estimation, introducing the concept of contact angle hysteresis, which is the difference between the advancing $\left(\theta_{a}\right)$ and receding $\left(\theta_{r}\right)$ contact angles of the probe liquid [20]. Based on this approach, the concisely-named $\mathrm{CAH}$, it is possible to evaluate the total SFE of the solid using only one probe liquid by measurements of advancing and receding contact angles (Equation (1)). Values of SFE estimated fromthe CAH approach presented in the next parts of this manuscript are represented by an arithmetic mean of surface free energy values $\left(\gamma_{s}\right)$ calculated separately from the contact angle hysteresis of water $\left(\gamma_{s}^{W}\right)$, formamide $\left(\gamma_{s}^{F}\right)$, and diiodomethane $\left(\gamma_{s}^{D M}\right)$.

\section{Results and Discussion}

The main aim of the study was to determine the changes in the surface properties of the PEEK support before and after modifications activating its surface with cold air plasma and depositing layers of biologically-active substances or their mixtures. In the aspect of biocompatibility, it should be emphasized that cold plasma treatment causes highly effective surface sterilization, killing $100 \%$ of living and sporulating microorganisms [8]. Besides the main aim of the biocompatibility increase of the PEEK surface, another is to improve the potential use of polymeric materials in tissue engineering. Polymers can carry therapeutic substances and can be used repeatedly thanks to cold plasma sterilization.

\subsection{Contact Angles}

\subsubsection{Plasma-Activated and Untreated PEEK Surfaces}

The values of advancing contact angles measured on the untreated PEEK surfaces were estimated as $87.5^{\circ}$ (Figure $4 \mathrm{~A}$ ), which is in the range of $75^{\circ}-95^{\circ}$ obtained by other authors [26-28]. Usually, the process of plasma treatment of polymers increases their surface polarity by introducing new surface functional groups rich in oxygen and/or nitrogen, which also increase the surface roughness in the micro-scale $[3,4,29]$. These statements were reflected in our experiments. The hydrophobic surface of PEEK after plasma activation became highly polar, which can be seen in Figure 4A. The water advancing contact angles dropped drastically from $87.5^{\circ}$ to $36.4^{\circ}$, while formamide completely spread on the activated PEEK surface even without forming a drop. Therefore, the contact angle was assumed to be zero, although on the unmodified PEEK surface it was measured as a high value of $70.0^{\circ}$. It is worth noting that the activation of PEEK by the cold air plasma did not affect the interactions with the non-polar diiodomethane (Figure 4A). 

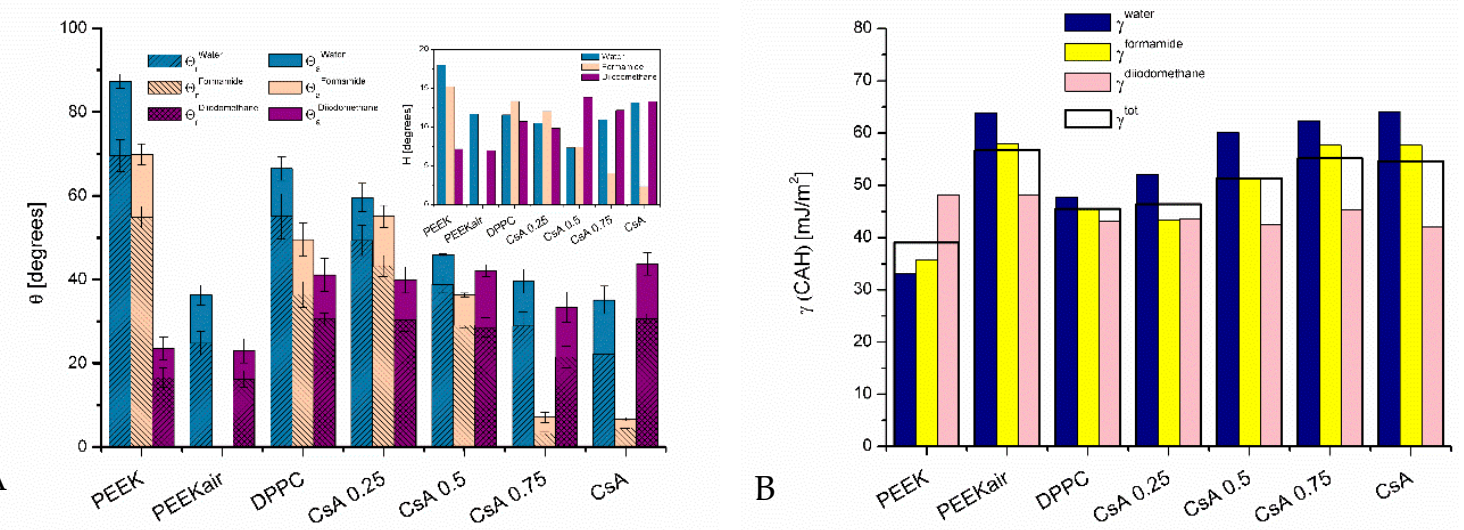

Figure 4. (A) - Advancing and receding contact angles of water, formamide, and diiodomethane and their hysteresis $(\mathrm{H}) ;(\mathbf{B})$ - Surface free energy $\left(\gamma_{s}\right)$ estimated from the contact angle hysteresis of water, formamide, and diiodomethane and their arithmetic mean $\left(\gamma_{s}^{\text {tot }}\right)$ for the modified PEEK surfaces.

\subsubsection{One-Component Monolayers}

In cases of studies of highly sensitive systems of monolayers of bioactive molecules deposited on a solid support, as suggested by Jurak [24], the time of the contact of the measuring liquid and the tested surface is a very important parameter. According to this study, to prevent the molecular orientation and creation of domains under the influence of the measuring liquid, the time of liquid-surface contact should be less than 10 seconds. Thus, in our experiment, the value of the advancing and receding contact angle was determined in less than 7 seconds of contacting the probe liquid with the evaluated surface.

The deposition of one or two-component layers of the selected biologically-active substances on the activated PEEK surface significantly influenced its polarity. In each case, an increase in the advancing contact angles of the measuring liquids was observed (Figures $4 \mathrm{~A}$ and $5 \mathrm{~A}$ ). The one-component films of DPPC and Chol interacted in a similar way with test liquids, respectively, and for PEEK/DPPC the following values were obtained: $\theta_{a}{ }^{\text {water }}=66.6^{\circ} ; \theta_{a}$ formamide $=49.7^{\circ} ; \theta_{a}$ diiodomethane $=41.2^{\circ}$ and for PEEK $/$ Chol: $\theta_{a}{ }^{\text {water }}=64.3^{\circ} ; \theta_{a}^{\text {formamide }}=51.3^{\circ} ; \theta_{a}$ diiodomethane $=35.0^{\circ}$. Nevertheless, the presence of CsA also caused changes in the surface wetting properties, but in a completely different way. The average values of the advancing contact angles of water remained unchanged compared to those on the plasma treated PEEK surface, similarly to the formamide droplets for which the contact angles were estimated as about 7.0 (Figures $4 \mathrm{~A}$ and $5 \mathrm{~A}$ ). However, in the case of diiodomethane, the impact caused by dispersion forces was much weaker and the advancing contact angles of this liquid were observed as $43.9^{\circ}$ (Figure $4 \mathrm{~A}$ ). The described results suggest how molecules of different substances interact with the activated PEEK surface and how they bind to it and/or arrange on the polymer. The high values of formamide advancing contact angles obtained for the DPPC and Chol layers compared to those on the plasma treated PEEK indicate that the hydrocarbon parts of the molecules are directed towards the air. The behavior of protein molecules is more complicated because CsA has a complex structure and a high possibility of conformational changes depending on the surrounding environment [30]. It forms loosely packed layers which allow liquids to be more intensely contacted with the surface of the polymer. Alternatively, the CsA molecules can attach to the surface of the polymer in such a way that their polar parts are directed towards the air. 
A

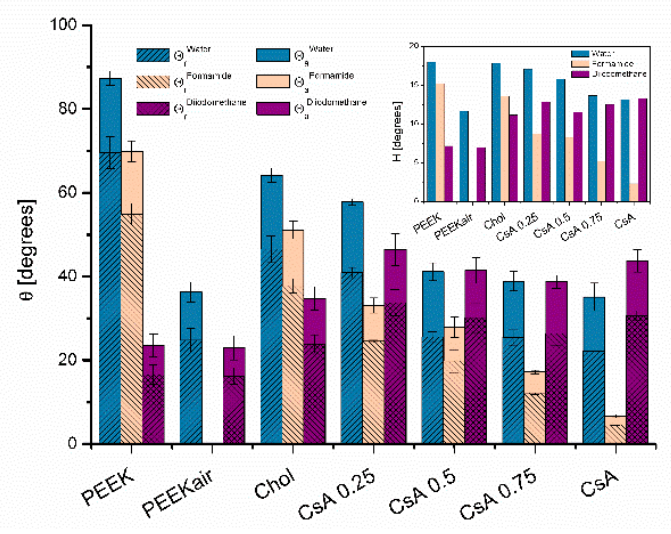

B

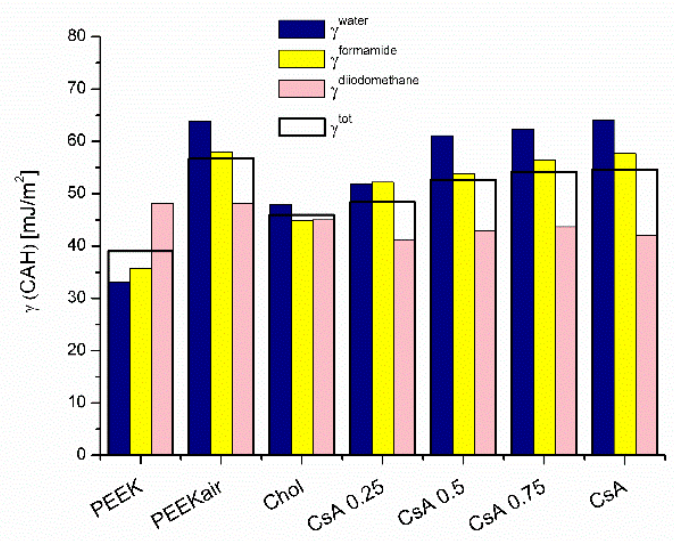

Figure 5. (A) —Advancing and receding contact angles of water, formamide and diiodomethane and their hysteresis $(\mathrm{H}) ;(\mathbf{B})$ - Surface free energy $\gamma_{s}$ estimated from the contact angle hysteresis of water, formamide, and diiodomethane and their arithmetic mean $\left(\gamma_{s}^{t o t}\right)$ for the modified PEEK surfaces.

\subsubsection{Binary Monolayers}

In the case of the two-compound DPPC-CsA or Chol-CsA coatings containing variable molar fractions of CsA peptide ( $\mathrm{X}_{\mathrm{CsA}}=0.25 ; 0.5$ and 0.75$)$, significant changes depending on the CsA content were observed, especially using the polar test liquids. For the DPPC-CsA systems the advancing contact angles of water at $\mathrm{X}_{\mathrm{CsA}}=0.25$ dropped from $66.6^{\circ}(\mathrm{DPPC})$ to $59.7^{\circ}\left(\mathrm{X}_{\mathrm{CsA}}=0.25\right)$ and gradually decreased to $46^{\circ}$ and $39.8^{\circ}$ for $\mathrm{X}_{\mathrm{CsA}}=0.5$ and 0.75 , respectively. Therefore, for the second polar liquid, formamide, also similar changes were observed: $\theta_{a}$ formamide $=55.2^{\circ} ; 36.4^{\circ}$ and $7.2^{\circ}$ at $\mathrm{X}_{\mathrm{CsA}}=0.25 ; 0.5$ and 0.75 , respectively (Figure $4 \mathrm{~A}$ ). In the case of the Chol-CsA systems deposited on the activated PEEK surface, the values of the advancing contact angles of polar liquids and their changes are very close to the DPPC-CsA system. As the amount of CsA in the Chol film increases, the contact angles of water and formamide decrease from $\theta_{a}$ water $=64.3^{\circ}$ and $\theta_{a}$ formamide $=51.3^{\circ}$ on the PEEK $/$ Chol coating to $\theta_{a}{ }^{\text {water }}=57.9^{\circ} ; 41.3^{\circ} ; 39^{\circ}$ and $\theta_{a}$ formamide $=33.2^{\circ} ; 28.0^{\circ} ; 17.3^{\circ}$ at $\mathrm{X}_{\mathrm{CsA}}=0.25 ; 0.5$ and 0.75 , respectively (Figure 5A). The revealed results suggest that the addition of CsA to the DPPC or Chol film on the PEEK support causes an increase in the strength of polar interactions between the polymer surface and polar liquids. Nevertheless, diiodomethane, a non-polar substance which interacts mainly by dispersive forces, for the DPPC-CsA system did not reveal significant changes as the amount of CsA increased $\left(\theta_{a}\right.$ diiodomethane $=41.2^{\circ} ; 40.0^{\circ} ; 42.3^{\circ}$ for DPPC; $\mathrm{X}_{\mathrm{CsA}}=0.25$ and 0.5$)$, respectively. However, only at the highest content of $\mathrm{CsA}, \mathrm{X}_{\mathrm{CsA}}=0.75$, was a decrease of the diiodomethane advancing contact angle to the value of $33.5^{\circ}$ (Figure $4 \mathrm{~A}$ ). A similar tendency was observed for the Chol-CsA coatings (Figure 5A). For the pure Chol layer deposited on the activated PEEK surface, the advancing contact angle of diiodomethane was estimated as $34.9^{\circ}$ and this value significantly increased (to $46.5^{\circ}$ ) as CsA was present in a molar ratio of 0.25 . Further addition of CsA to the Chol layer caused a slight decrease of $\theta_{a}$ diiodomethane $=41.6^{\circ}$ and $38.1^{\circ}$ at $\mathrm{X}_{\mathrm{CsA}}=0.5$ and 0.75 , respectively. Above results suggest the weak dispersive interactions between diiodomethane test liquid and modified PEEK surface for coatings composed of DPPC-CsA at $\mathrm{X}_{\mathrm{CsA}}=0.5\left(\theta_{a}\right.$ diiodomethane $\left.=42.3^{\circ}\right)$ and Chol-CsA at $\mathrm{X}_{\mathrm{CsA}}=0.25$ $\left(\theta_{a}\right.$ diiodomethane $\left.=46.5^{\circ}\right)($ compare Figures $4 \mathrm{~A}$ and $5 \mathrm{~A})$.

The values of receding contact angles of probe liquids are necessary to obtain contact angle hysteresis $(\mathrm{H})$ and evaluate surface free energy $\left(\gamma_{s}\right)$ from the CAH approach. It was obvious that for the described systems the tendency of the receding contact angle changes would be the same as for advancing ones (Figures $4 \mathrm{~A}$ and $5 \mathrm{~A}$ ). The highest values of receding contact angles of polar liquids were observed for the pure DPPC $\left(\theta_{r}{ }^{\text {water }}=55^{\circ}\right)$ and DPPC- $X_{\mathrm{CsA}}=0.25\left(\theta_{r}\right.$ formamide $\left.=43.1^{\circ}\right)$ coatings . The lowest ones were observed for the CsA $\left(\theta_{r}{ }^{\text {water }}=22.1^{\circ}\right)$ and DPPC- $\mathrm{X}_{\mathrm{CsA}}=0.25\left(\theta_{r}\right.$ formamide $\left.=3.1^{\circ}\right)$ films (Figure $4 \mathrm{~A}$ ). In the case of non-polar diiodomethane, the highest values of receding contact angles 
were revealed on Chol- $\mathrm{X}_{\mathrm{CsA}}=0.25\left(\theta_{r}{ }^{\text {diiodomethane }}=33.7^{\circ}\right)$ and the lowest ones on DPPC- $\mathrm{X}_{\mathrm{CsA}}=0.75$ $\left(\theta_{r}\right.$ diiodomethane $\left.=21.4^{\circ}\right)($ Figures $4 \mathrm{~A}$ and $5 \mathrm{~A})$.

\subsection{Contact Angle Hysteresis}

Insets in Figures 4A and 5A present the values of contact angle hystereses $(\mathrm{H})$ of three test liquids determined for all from the modified PEEK surfaces. However, the percentage differences $\left(\frac{H * 10 \% \%}{\theta_{a}^{\text {liquid }}}\right)$ between the advancing and receding contact angles of each liquid are variable depending on the surface composition and polarity. To fully describe the phenomena on the polymer surface, the behavior of the molecules during a film compression and transfer onto the polymer support should be considered. It is necessary to take into account the morphology, thickness, and intermolecular interactions between monolayer compounds during the process using the Langmuir trough. The previous research conducted by our team $[31,32]$ as well as by other authors $[33,34]$ has shown that at the interface between water and air, DPPC-CsA and Chol-CsA are in the state of expanded liquid, which is characterized by loose packing of molecules. This state is determined by the repulsion between components (negative values of excess Gibbs energy of mixing) [35]. We assumed that the basic physicochemical properties of the monolayer do not change when transferred to a polymer substrate. Therefore, the looser film is more permeable to the liquid, and thus affects the value of the contact angle hysteresis, because the liquid can penetrate deeper when measuring the receding contact angle. For instance, for the water contact angles, it changes from a minimum of $16 \%$ for DPPC-CsA at $\mathrm{X}_{\mathrm{CsA}}=0.5$ to $38.3 \%$ for Chol-CsA at $\mathrm{X}_{\mathrm{CsA}}=0.5$ (Insets in Figures $4 \mathrm{~A}$ and $5 \mathrm{~A}$ ). The percentage difference between the average advancing and receding contact angles was estimated as $23.2 \%$ (water), $32.0 \%$ (formamide), and 30.0\% (diiodomethane) for PEEK coated with DPPC, CsA, and binary DPPC-CsA layers. For second system including $\mathrm{Chol}, \mathrm{CsA}$ and mixed Chol-CsA layers, those differences were evaluated as $33.6 \%$ (water), $28.2 \%$ (formamide) and 30.0\% (diiodomethane). During the advancing contact angle measurement, the probe liquid interacts with the monolayer deposited on the polymer plate similarly as in the other measurements [22]. In consequence, there may occur many phenomena such as the reorientation of molecules, their aggregation (e.g., under the influence of a liquid, e.g., water) or even desorption if the adhesion forces to the solid surface are insufficient [22]. According to Belman et al. [23], the lipid monolayer upon contacting with water probe liquid can even transform to the bilayer structure partially, leaving holes in the film and facilitates the liquid penetration into the layer during the measurement of receding contact angle, thus giving rise to the contact angle hysteresis. It should be taken into account that similar mechanisms can occur in our systems.

\subsection{Surface Free Energy}

In fact, to have better insight into the changes of surface wetting properties the further analysis of the binary DPPC-CsA and Chol-CsA monolayers was conducted based on the values of surface free energy. They were estimated from the $\mathrm{CAH}$ approach (described precisely in the introduction) using the advancing and receding contact angles of each probe liquid separately and then an arithmetic mean of these three values (as total one) was determined $\left(\gamma_{s}^{\text {tot }}\right)$.

The cold air plasma activation caused the significant increase of $\gamma_{s}^{\text {water }}$ of PEEK surface free energy from value 33.1 to $63.8 \mathrm{~mJ} / \mathrm{m}^{2}$ and $\gamma_{s}^{\text {formamide }}$ from 35.8 to $58.0 \mathrm{~mJ} / \mathrm{m}^{2}$. However, no essential change in $\gamma_{s}^{\text {diiodomethane }}$ was observed, i.e., $48.1 \mathrm{~mJ} / \mathrm{m}^{2}$ before and $48.2 \mathrm{~mJ} / \mathrm{m}^{2}$ after plasma treatment. The above results can prove the creation of highly polar groups on the PEEK surface after plasma modification, which seem not to affect the dispersive interactions with diiodomethane. The $\gamma_{s}^{\text {tot }}$ value of PEEK rises from 39.0 to $56.7 \mathrm{~mJ} / \mathrm{m}^{2}$ (Figure 4B). These findings are in agreement with those of other authors (increase from about 40.0 to $55 \mathrm{~mJ} / \mathrm{m}^{2}$ after $60 \mathrm{~s}$ cold plasma treatment was observed) the more that the PEEK came from another factory [36]. Moreover, it should be announced that cold plasma treatment of PEEK surfaces above $60 \mathrm{~s}$ does not change its surface free energy significantly and the memory effect of surface free energy appears. Additionally, the surface free energy of plasma activated PEEK surfaces (60 s) did not change significantly up to $48 \mathrm{~h}$ of storage after plasma treatment according 
to Rymuszka et al. [36]. As mentioned before, a deposition of one component Chol, DPPC, or CsA monolayer induced the substantial decrease of $\gamma_{S}$ of PEEK surface free energy estimated from contact angles of each test liquids, especially polar ones comparing to those measured on the activated surface $\left(\gamma_{s}^{\text {water }}=63.8 \mathrm{~mJ} / \mathrm{m}^{2} ; \gamma_{s}^{\text {formamide }}=58.0 \mathrm{~mJ} / \mathrm{m}^{2} ; \gamma_{s}^{\text {diiodomethane }}=48.2 \mathrm{~mJ} / \mathrm{m}^{2}\right)$. Presence of the DPPC film caused the decrease of $\gamma_{s}^{\text {water }}$ by $16.0 \mathrm{~mJ} / \mathrm{m}^{2}, \gamma_{s}^{\text {formamide }}$ by $12.4 \mathrm{~mJ} / \mathrm{m}^{2}$ and $\gamma_{s}^{\text {diiodomethane }}$ only by $5.1 \mathrm{~mJ} / \mathrm{m}^{2}$. The similar decrease was observed in the case of the Chol coating, $\gamma_{s}^{\text {water }}$ by $15.9 \mathrm{~mJ} / \mathrm{m}^{2}$, $\gamma_{s}^{\text {formamide }}$ by $13.1 \mathrm{~mJ} / \mathrm{m}^{2}$ and $\gamma_{s}^{\text {diiodomethane }}$ by $3.2 \mathrm{~mJ} / \mathrm{m}^{2}$. However, the pure CsA film changed the surface polarity in a different way. There were observed a little increase in $\gamma_{s}^{\text {water }}$ by $0.3 \mathrm{~mJ} / \mathrm{m}^{2}$ and a slight decrease in $\gamma_{s}^{\text {formamide }}$ by $0.4 \mathrm{~mJ} / \mathrm{m}^{2}$ as regards the PEEKair surface. Surprisingly, the biggest change occurred in $\gamma_{s}^{\text {diiodomethane }}$ which decreased by about $6.2 \mathrm{~mJ} / \mathrm{m}^{2}$ (Figures $4 \mathrm{~B}$ and $5 \mathrm{~B}$ ). The $\gamma_{s}^{\text {tot }}$ values of the PEEK surfaces coated with DPPC and Chol described above fell from $56.7 \mathrm{~mJ} / \mathrm{m}^{2}$ (PEEKair) to $45.5 \mathrm{~mJ} / \mathrm{m}^{2}$ for DPPC and $45.9 \mathrm{~mJ} / \mathrm{m}^{2}$ for Chol films. However, $\gamma_{s}^{\text {tot }}$ of the CsA coating revealed a smaller decrease by $2.1 \mathrm{~mJ} / \mathrm{m}^{2}$ (Figures $4 \mathrm{~B}$ and $5 \mathrm{~B}$ ). Introduction of the CsA molecules to the Chol or DPPC monolayers in each case generated the slight increase of the obtained $\gamma_{s}^{\text {tot }}$. Moreover, as the amount of CsA increased, the values of $\gamma_{s}^{\text {tot }}$ increased as well, reaching the highest value at $\mathrm{X}_{\mathrm{CsA}}=0.75\left(\gamma_{s}^{\text {tot }}=55.1 \mathrm{~mJ} / \mathrm{m}^{2}\right)$ for the DPPC-CsA films and $54.2 \mathrm{~mJ} / \mathrm{m}^{2}$ for the Chol-CsA film. The latter one was nearly the same as for the pure CsA film $\left(\gamma_{s}^{t o t}=54.6 \mathrm{~mJ} / \mathrm{m}^{2}\right)$ (Figures $4 \mathrm{~B}$ and $5 \mathrm{~B}$ ).

The last figure (Figure 6) represents the changes in the $\gamma_{s}^{\text {tot }}$ values of deposited monolayers as the molecules of one component (DPPC or Chol) have been replaced by CsA, i.e., as the molar fraction of CsA in the mixed monolayer increases. In all studied cases except system (Chol-CsA 0.75), the addition of CsA to the DPPC or Chol film caused a little increase of the $\gamma_{s}^{\text {tot }}$ value. These results confirm the significant impact of CsA on the organization and behavior of layers of biologically active substances mimicking the biological membranes (DPPC and Chol). Similar effects were observed by other authors [34,37].

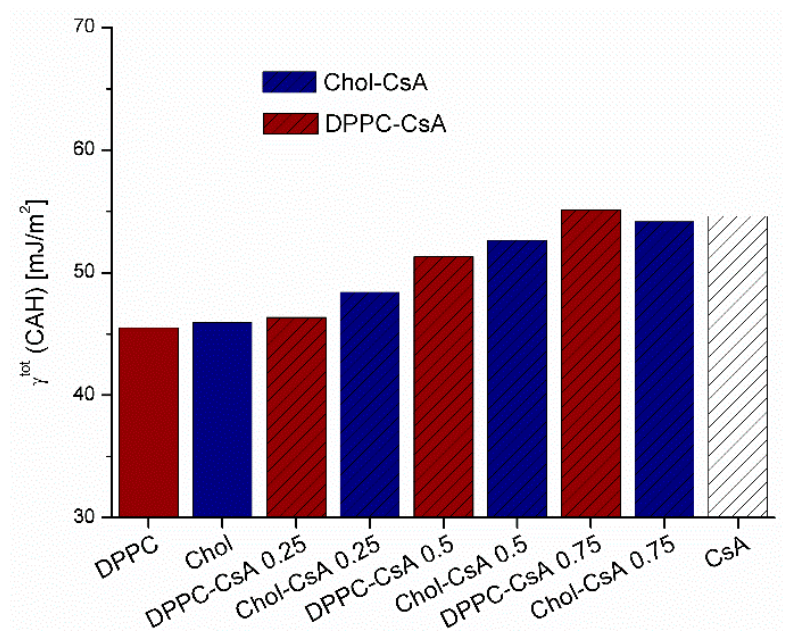

Figure 6. Total surface free energy $\left(\gamma_{s}^{\text {tot }}\right)$ estimated from the contact angle hysteresis of water, formamide, and diiodomethane by its arithmetic mean for differently coated PEEK surfaces.

In the presented manuscript, the polymer surfaces were coated with thin films of bioactive substances. It is likely that the changes in its surface free energy result from the contact angle hysteresis. From the literature, it is known that this parameter is due to largely the liquid penetration inside film structure and/or molecules reorganization [23], as well as the liquid film remaining beyond the droplet after receding the three-phase contact line [24]. As it was mentioned previously in the case of monolayer coatings, the contact angles depend on their permeability relative to the test liquids. A more ordered and packed monolayer is then the contact angle, and its hysteresis can be less affected by the polymeric support surface. However, as reported by other authors [22], DPPC layer deposited on mica forms a packed layer, giving a high contact angle but with longer contact with polar liquids 
during the measurement of receding contact angles, there is a spontaneous reorganization of the layer and the receding angle is already much lower, and therefore, adequately high hysteresis occurs. On the other hand, on the loosely packed DOPC layers lower advancing contact angles are obtained, but also the hysteresis is usually smaller than for those packed like DPPC. So, all investigated cases should be considered in relation to specific arrangements [22]. In the case of the systems described in this paper, the PEEK surface was activated by cold plasma prior to the coating process, which was supposed to increase the adhesion of molecules to its surface. However, in the case of such high energy surfaces, apart from the strong physical adhesion, we cannot explicitly exclude the creation of the chemical bonds between the thin film and polymer surface. Understanding the origin and the nature of the hysteresis contact angle is especially important when describing changes in the surface free energy using the $\mathrm{CAH}$ model. However, dissimilar behavior of probe liquids and in particular their contact angle hystereses seem to be strictly connected with the mechanism of film penetration/retention as well as with the surface roughness [38].

\subsection{Surface Topography}

Investigation of the topography and roughness of PEEK surfaces using the optical profilometry revealed changes in the roughness parameters $\left(R_{a}, R_{q}, R_{t}\right)$ depending on the kind of modification (Figure 7). As expected, the low temperature and low-pressure air plasma caused increase of the PEEK roughness in micro-scale, giving the $R_{a}$ an increase from about 0.7 to $0.8 \mu \mathrm{m} ; R_{q}$ from 0.85 to $1.00 \mu \mathrm{m}$ and $R_{t}$ from 8.7 to $11.3 \mu \mathrm{m}$, which is in agreement with the experiments already conducted by Wiącek et al. [3,4].

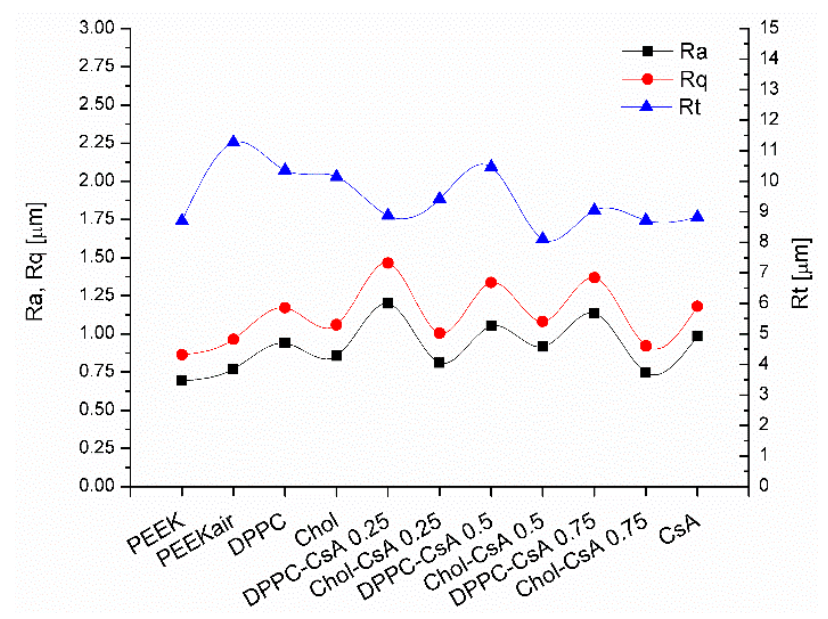

Figure 7. Roughness parameters $\left(R_{a}, R_{q}, R_{t}\right)$ of PEEK andmodified PEEK surfaces.

Deposition of one and/or two-component layers on the activated PEEK support always leads to the rise of the values of the $R_{a}$ and $R_{q}$ roughness parameters compared to those of the PEEKair sample (Figure 7). This observation results in conclusions about the formation of nano-scale irregularity onto micro-scale PEEK roughness caused by the layer preparation which can be enhanced by the PEEK plasma activation. This process was already observed on cold plasma activated PEEK surfaces after deposition of phospholipids by Jurak et al. [13]. Of the two-component films, the greater surface roughness of PEEK was observed after modification with the DPPC-CsA system compared to the Chol-CsA system. This can give information about the formation of another, possibly more compact structure with different homogeneity on the PEEKair surface. Figure 8 shows the most representative images of the obtained PEEK surfaces with the roughness parameters. 


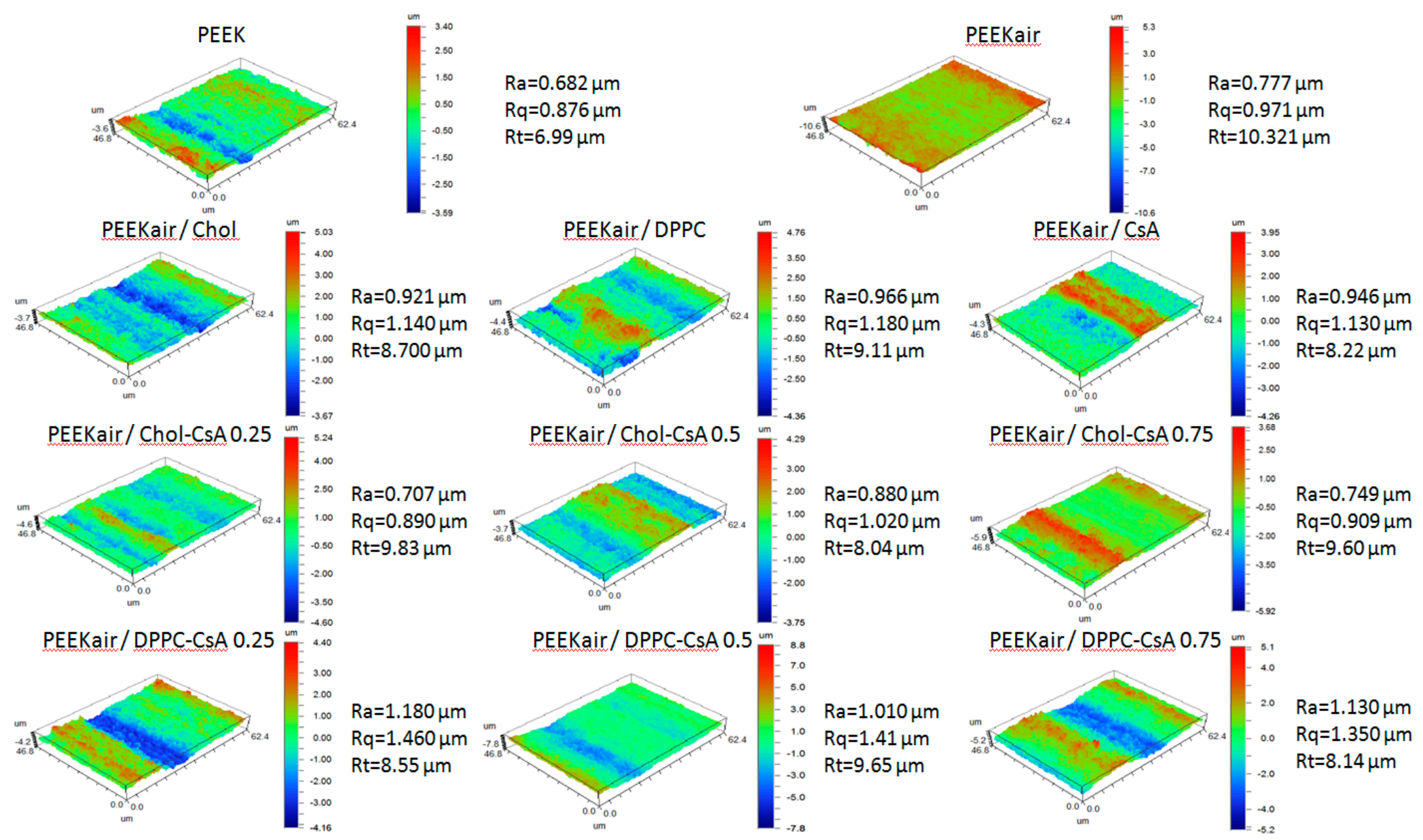

Figure 8. The most representative images of the obtained PEEK surfaces $\left(62 \times 47 \mu \mathrm{m}^{2}\right)$ with the roughness parameters. 
On the basis of obtained topography images, one can state that the polymeric support plays a main role in the process of thin film deposition as well as cold plasma activation. As an effect, the same monolayer transferred onto a different solid support can reveal totally different behavior and properties [39]. Therefore, the interactions between the deposited monolayer and activated polymeric support are varied and can be determined by different types of factors: van der Waals forces, entropic forces, and hydration forces. The surface roughness and the kind of biological film can determine the magnitude of the above interactions [40]. In order to obtain the layer stability, the investigated systems should achieve a minimum of the interaction potential energy determined mainly by the layer composition.

It should be taken into account that the rough support hinders the formation of the homogeneous monolayers/coatings due to high energetic costs dealing with tight adherence. Despite that, the monolayers were effectively transferred onto the activated PEEK and their presence affected the measured contact angles as well as the determined surface free energy values depending on the film composition. Thus, both the PEEK roughness and the deposited monolayer were found to determine the wettability changes. It is believed that principal properties (molecular orientation, packing, ordering) of the original Langmuir monolayers obtained at the air/water interface were maintained after transferring even though some redistribution of the molecules in the mixed DPPC(Chol)-CsA films can take place. In consequence, an imperfect coating can create the hierarchical arrangement where nanometer-sized monolayers are attached to the micrometer-sized PEEK highs and/or fill depressions in the polymer surface. These aspects seem to be essential for the origin of the contact angle hysteresis when the liquid penetrates the surface cavities during the three-phase contact line receding. In the present paper, the roughness of the one component layers was very similar, but only for the DPPC and Chol surface, the analogous values of surface free energy were obtained. Although in the case of the CsA layer the roughness is comparable to that of DPPC and Chol, the total surface free energy significantly increased (Figures 6 and 7). For the mixed films, the highest values of the $R_{a}$, $R_{q}$ and $R_{t}$ parameters were obtained for the DPPC-CsA surface at $\mathrm{X}_{\mathrm{CsA}}=0.5$ and 0.75 , and the best correlation between them, which can suggest that the biomolecules are homogeneously distributed over the PEEK surface. Moreover, the highest roughness obtained for DPPC-CsA 0.75 corresponds to the highest value of the total surface free energy (Figure 6). However, no exact correlation between the CsA content and the roughness parameters was found. Similar relationships between the roughness parameters appeared also for the binary Chol-CsA systems, but the values were lower than those obtained for the mixed films containing DPPC, and likewise, the surface free energy values. Compared to the Chol-CsA layers, DPPC with CsA forms more extensive domains with a brush structure due to the presence of the long acyl DPPC chains capable of forming the lamellar structures. Such behavior of the DPPC-CsA layers is caused by stronger repulsion between their molecules confirmed by the high excess Gibbs energy values (unpublished data). Thus, received surfaces are intended to have potential application in regenerative medicine to develop biomimetic strategies for artificial bone grafts in tissue engineering.

\section{Conclusions}

The presented results confirm the formation of Langmuir-Blodgett films on the cold plasma activated PEEK polymer. Significant changes in the values of advancing and receding contact angles of the measuring liquids clearly indicate that, depending on the composition of the film, the polarity of the surface changes. By using the Chibowski approach based on the contact angle hysteresis values of a given liquid, it was possible to estimate changes in the surface free energy of the biological modified PEEK surfaces. The one component (DPPC, Chol, CsA) and binary (DPPC-CsA, Chol-CsA) monolayers noticeably alter the PEEK surface, which also was revealed in the change of the roughness parameters of the modified PEEK surfaces. This affects the type and magnitude of interaction, which manifests itself in changes in the value of the surface free energy. The obtained results may be helpful in the development of a new generation of polymer coatings exhibiting biocompatible and 
immunosuppressive properties in different processes, for example, reducing inflammation, accelerating wound healing, and preventing the rejection of implants.

Author Contributions: Conceptualization, methodology, and formal analysis: K.P., K.W., M.J. and A.E.W.; Writing-original draft preparation and visualization: K.P. and K.W.; Writing-review, editing, and supervision: M.J. and A.E.W.

Funding: This research received no external funding.

Conflicts of Interest: The authors declare no conflict of interest.

\section{References}

1. Kurtz, S.M. An overview of PEEK biomaterials. In PEEK Biomaterials Handbook, 1st ed.; William Andrew: Kindlington, UK, 2011; pp. 1-8.

2. Ma, R.; Tang, T. Current strategies to improve the bioactivity of PEEK. Int. J. Mol. Sci. 2014, 15, 5426-5445. [CrossRef] [PubMed]

3. Wiącek, A.E.; Terpiłowski, K.; Jurak, M.; Worzakowska, M. Low-temperature air plasma modification of chitosan-coated PEEK. Polym. Test. 2016, 50, 325-334. [CrossRef]

4. Wiacek, A.E.; Terpiłowski, K.; Jurak, M.; Worzakowska, M. Effect of low-temperature plasma on chitosan-coated PEEK polymer characteristics. Eur. Polym. J. 2016, 78, 1-13. [CrossRef]

5. $\quad$ Evans, N.T.; Torstrick, F.B.; Lee, C.S.D.; Dupont, K.M.; Safranski, D.L.; Chang, W.A.; Macedo, A.E.; Lin, A.; Boothby, J.M.; Whittingslow, D.C.; et al. High strenght, surface porous poly-ether-ether-ketone orthopaedic implants. Acta Biomater. 2015, 13, 159-167. [CrossRef]

6. Walsh, W.R.; Bertollo, N.; Christou, C.; Schaffiner, D.; Mobbs, R.J. Plasma-sprayed titanium coating to polyetheretherketone improves the bone-implant interface. Spine J. 2015, 15, 1041-1049. [CrossRef] [PubMed]

7. Lvhua, L.; Yanyan, Z.; Xiong, Z. Bioactive polyetheretherketone implant composites for hard tissue. Prog. Chem. 2017, 29, 450-458. [CrossRef]

8. Gan, K.; Liu, H.; Jiang, L.; Liu, X.; Song, X.; Niu, D.; Chen, T.; Liu, C. Bioactivity and antibacterial effect of nitrogen plasma immersion ion implantation on polyetheretherketone. Dent. Mater. 2016, 32, 10263-10274. [CrossRef]

9. Civantos, A.; Martinez-Campos, E.; Ramos, V.; Carlos, E.; Gallardo, A.; Abarrategi, A. Titanium coatings and surface modifications: Toward clinically useful bioactive implants. ASC Biomater. Sci. Eng. 2017, 3, 1245-1261. [CrossRef]

10. Willumeit, R.; Feyersbend, F. Phospholipids as implant coatings. J. Mater. Sci. Mater. Med. 2007, 18, 367-380. [CrossRef]

11. Tateishi, T.; Kyomoto, M.; Kakinoki, S.; Yamaoka, T.; Ishihara, K. Reduced platelets and bacteria adhesion on poly(ether etherketone) by photoinduced and self-initiated graft polymerization of 2-methacryloyloxyethyl phosphorylcholine. J. Biomed. Mater. Res. A 2014, 102, 1342-1349. [CrossRef]

12. Iwasaki, Y.; Ishihara, K. Cell membrane-inspired phospholipid polymers for developing medical devices with excellent biointerfaces. Sci. Technol. Adv. Mater. 2012, 13, 064101. [CrossRef] [PubMed]

13. Jurak, M.; Wiącek, A.E.; Terpiłowski, K. Properties of PEEK-supported films of biological substances prepared by the Langmuir-Blodgett technique. Colloids Surf. A 2016, 510, 263-274. [CrossRef]

14. Jurak, M.; Wiącek, A.E.; Mroczka, R.; Łopucki, R. Chitosan/phospholipid coated polyethyleneterephthalate (PET) polimer surfaces activated by air plasma. Colloids Surf. A 2017, 532, 155-164. [CrossRef]

15. Liefeith, K.; Frant, M. Archaeal tetraether lipid coatings-A strategy for the development of membrane analog spacer systems for the site-specific functionalization of medical surfaces. Biointerphases 2018, 13, 011004. [CrossRef]

16. De Leo, V.; Mattioli-Belmonte, M.; Cimmarusti, M.T.; Panniello, A.; Dicarlo, M.; Milano, F.; Agostiano, A.; De Giglio, E.; Catucci, L. Liposome-Modified titanium surface: A strategy to locally deliver bioactive molecules. Colloids Surf. B 2017, 158, 387-396. [CrossRef] [PubMed]

17. Willumeit, R.; Feyerabend, F.; Kamusewitz, H.; Schossig, M. Biological multi-layer systems as implant Surface modification. Materialwissenschaft und Werkstofftechnik 2003, 34, 1084-1093. [CrossRef]

18. Rochford, E.T.; Poulsson, A.H.; Salavarrieta, V.J.; Lezuo, P.; Richards, R.G.; Moriarty, T.F. Bacterial adhesion to orthopaedic implant materials and a novel oxygen plasma modified PEEK surface. Colloids Surf. B 2014, 113, 213-222. [CrossRef] [PubMed] 
19. Gil'man, A.B. Low-temperature plasma treatment as an effective method for surface modification of polymeric materials. High Energy Chem. 2003, 37, 17-23. [CrossRef]

20. Chibowski, E. Surface free energy of a solid from contact angle hysteresis. Adv. Colloid Interface Sci. 2003, 103, 149-172. [CrossRef]

21. Chibowski, E. Some problems of characterization of solid surface via the surface free energy changes. Adsorpt. Sci. Technol. 2017, 35, 647-659. [CrossRef]

22. Jurak, M. Changes in stability of the DPPC monolayer during its contact with the liquid phase. Chem. Phys. Lipids 2012, 165, 302-310. [CrossRef] [PubMed]

23. Belman, N.; Jn, K.; Golan, Y.; Israelachvili, J.N.; Pesika, N.S. Origin of the contact angle hysteresis of water on chemisorbed and physisorbed self-assembled monolayers. Langmuir 2012, 28, 14609-14617. [CrossRef]

24. Jurak, M. Contact angle hysteresis and phase separation in dry phospholipid films with cholesterol deposited on mica surface. Appl. Surf. Sci. 2015, 328, 596-605. [CrossRef]

25. Wnętrzak, A.; Makyła-Juzak, K.; Chachaj-Brekiesz, A.; Lipiec, E.; Romeu, N.V.; Dynarowicz-Łątka, P. Cyclosporin A distribution in cholesterol-sphingomyelin artificial membranes modeled as Langmuir monolayers. Colloids Surf. B Biointerfaces 2018, 166, 286-294. [CrossRef] [PubMed]

26. Ha, S.W.; Hauert, R.; Ernst, K.H.; Winter, E.; Wintermantel, E. Surface analysis of chemically-etched and plasma-treated polyetheretherketone (PEEK) for biomedical applications. Surf. Coat. Technol. 1997, 96, 293-299. [CrossRef]

27. De Bartolo, L.; Gugluizza, A.; Morelli, S.; Cirillo, B.; Gordano, A.; Drioli, E. Novel PEEK-WC membranes with lows plasma protein affinity related to surface free energy parameters. J. Mater. Sci. Mater. Med. 2004, 15, 877-883. [CrossRef] [PubMed]

28. Zhang, S.; Awaja, F.; James, N.; McKenzie, D.R.; Ruys, A.J. A comparison of the strength of autohesion of plasma treated amorphous and semi-crystalline PEEK films. Polym. Adv. Technol. 2011, 22, 2496-2502. [CrossRef]

29. Terpiłowski, K.; Jurak, M.; Wiacek, A.E. Influence of nitrogen plasma treatment on the wettability of polyetheretherketone and deposited chitosan layers. Adv. Polym. Technol. 2018, 37, 1557-1569. [CrossRef]

30. El Taya, N.; Mark, A.E.; Vallat, P.; Brunne, R.M.; Testa, B.; van Gunsteren, W.F. Solvent-dependent conformation and hydrogen-bonding capacity of cyclosporin A: Evidence from partition coefficients and molecular dynamics simulations. J. Med. Chem. 1993, 36, 3757-3764. [CrossRef]

31. Przykaza, K.; Woźniak, K.; Jurak, M.; Wiącek, A.E. Properties of Langmuir and Langmuir-Blodgett monolayers of cholesterol-cyclosporine A on water and polymer support. Adsorption 2019, submitted.

32. Przykaza, K.; Woźniak, K.; Jurak, M.; Wiącek, A.E. Characteristics of polypeptide/phospholipid monolayers on water and plasma activated PEEK support. J. Surfactants Deterg. 2019, submitted.

33. Dynarowicz, P.; Wnętrzak, P.; Makyła-Juzak, K. Cyclosporin A in membrane lipid environment: Implications for antimalarian activity of the drug-The Langmuir monolayer studies. J. Membr. Biol. 2015, 248, 1021-1032. [CrossRef] [PubMed]

34. Soderlund, T.; Lehtonen, J.Y.A.; Kinnunen, P.K.J. Interactions of cyclosporin A with phospholipid membranes: Effect of cholesterol. Mol. Pharmacol. 1999, 55, 32-38. [CrossRef] [PubMed]

35. Gaines, G.L. Insoluble Monolayers at Liquid-Gas Interface; Wiley-Interscience: New York, NY, USA, 1966.

36. Rymuszka, D.; Terpiłowski, K.; Borowski, P.; Hołysz, L. Time-dependent changes of surface properties of polyether ether ketone caused by air plasma treatment. Polym. Int. 2016, 65, 827-834. [CrossRef]

37. O'Learyl, T.; Ross, P.; Lieber, M.; Levin, I. Effects of cyclosporine A on biomembranes: Vibrational spectroscopic, calorimetric and hemolysis studies. Biophys. J. 1986, 49, 795-801. [CrossRef]

38. Sedev, R.V.; Petrov, J.G.; Neumann, J.G. Effect of swelling of a polymer surface on advancing and receding contact angles. J. Colloid Interfacial Sci. 1996, 180, 36-42. [CrossRef]

39. Scomparin, C.; Lecuyer, S.; Ferreira, M.; Charitat, T.; Tinland, B. Diffusion in supported lipid bilayers: Influence of substrate and preparation technique on the internal dynamics. Eur. Phys. J. E 2009, 28, 211-220. [CrossRef] [PubMed]

40. Richter, R.P.; Maury, N.; Brisson, A.R. On the effect of the solid support on the interleafed distribution of lipids in supported lipid bilayers. Langmuir 2005, 21, 299-304. [CrossRef] [PubMed]

(C) 2019 by the authors. Licensee MDPI, Basel, Switzerland. This article is an open access article distributed under the terms and conditions of the Creative Commons Attribution (CC BY) license (http:/ / creativecommons.org/licenses/by/4.0/). 